Article

\title{
Epidemiological aspects, haematological and biochemical alter- ations in some gastrointestinal parasitic diseases of carnivores
}

\author{
Marius Stelian Ilie ${ }^{1 *}$, Roxana Gabriela Oanea ${ }^{2}$, Mirela Imre ${ }^{1}$, Iasmina Luca 1, Tiana Florea ${ }^{1}$, Simona Giubega ${ }^{1}$, \\ Gabriel Orghici ${ }^{3}$, Sorin Morariu ${ }^{1}$
}
1 Department of Parasitology and Dermatology, Banat's University of Agricultural Sciences and Veterinary Medicine "King Michael I of Romania", Faculty of Veterinary Medicine, no. 119, Calea Aradului, 300645, Timisoara, Romania, marius.ilie@fmvt.ro; mirela.imre@gmail.com; iasminaluca0@gmail.com; sujic.ti- jana@gmail.com; simonagiubega@gmail.com; sorin.morariu@fmvt.ro;
2 Banat's University of Agricultural Sciences and Veterinary Medicine "King Michael I of Romania", Faculty of Veterinary Medicine; oanea.roxana3@gmail.com;
3 Department of Veterinary Emergency, Banat's University of Agricultural Sciences and Veterinary Medicine "King Michael I of Romania", Faculty of Veterinary Medicine, no. 119, Calea Aradului, 300645, Timisoara, Romania gabrielorghici@gmail.com;
* Correspondence: $\underline{\text { marius.ilie@fmvt.ro }}$

\begin{abstract}
Gastrointestinal parasites are widespread pathogenic agents and one of the main causes for mortality in young dogs and cats. Many of these zoonotic parasites are relevant in terms of public health. The presence of parasites in the animal organism causes local and general modifications in the various organs they parasitize or transit throughout their life cycle. The present study aimed to identify the most frequent gastrointestinal parasites of dogs and cats and to monitor the alterations that occur in terms of haematological and biochemical parameters. The studied animals, 25 dogs and three cats from Timiș and Caraș Severin counties, were brought to the On-call room of the University Clinics of the Faculty of Veterinary Medicine Timişoara. The laboratory methods that were used were the Willis flotation method, the Baerman larvoscopic method and the Lugol method. The haematological methods, namely flow cytometry, cytochemistry and spectrophotometry, were performed at Bioclinica Laboratories, on whole blood samples that were collected in EDTA or simple tubes. The studied animals were positive for Giardia, Cystoisospora, Dipylidium, Ancylostoma, Toxocara and Trichocephalus. The positivity rate was $57.14 \%$, with prevalence rates according to the parasitic species ranging from $3.57 \%$ to $21.42 \%$, with multiparasitism in $32.14 \%$, and monoparasitism in $17.85 \%$. The values recorded for red blood cells, haemoglobin and hematocrit followed the same trendmost of the animals being situated within physiological values, except for three dogs, that recorded values below the minimal level. In the case of $\mathrm{MCH}$ (mean corpuscular haemoglobin) and MCHC (mean corpuscular haemoglobin concentration) the values recorded for most dogs were within physiological limits, except for three dogs which overpassed the maximum level. Eosinophils were high in all dogs, which is a characteristic feature of parasitism. The serum urea concentrations revealed the fact that all for dogs that were taken into study had values above the maximum limit.
\end{abstract}

Keywords: dog; cat; gastrointestinal parasites; haematological and biochemical parameters.

Received: 14.08 .2021

Accepted: 01.09.2021

Published: 09.09.2021

DOI: $10.52331 / c v j . v 26 i 2.25$

Copyright: () 2021 by the authors. Submitted for possible open access publication under the terms and conditions of the Creative Commons Attribution (CC BY) license (http://creativecommons.org/licenses /by/4.0/).

\section{Introduction}

Both dogs (Canis lupus familiaris), and cats (Felis catus) are domestic animals that have maintained tight bonds with humans and were bred and kept out of various reasons: as pets, as hunting dogs, police and utilitary animals, laboratory animals and in the case of cats, for rodent-control.

Intestinal parasites, including protozoa and helminths, are among the most widespread pathogenic agents encountered by veterinarians, being one of the main causes for mortality in young dogs and cats.

Dogs can serve as definitive host for a variety of macroparasites, microorganisms and viruses. They are associated with tens of zoonotic diseases which bear a negative 
impact on human and animal health [1,2]. The most important ones are rabies, echinococosis, toxacariasis, ancylostomiasis, giardiasis, etc.

Many of these zoonotic parasites are relevant in terms of public health. Their transmission occurs by means of parasitic elements such as eggs or larvae. The resistance of eggs in the environment is quite high. In temperate areas, eggs can survive from 6 to 12 months and the most commonly used disinfectants are not effective against them [3].

Gastrointestinal parasites have undergone a successful evolutionary process and have managed to survive and move with the use of various organ systems of hosts. The result of such infections can vary from subclinical to severe, life-threatening ones. They can cause serious health issues translated through delayed growth, precarious health conditions, low resistance to other concurrent diseases and decreased productivity [4].

The presence of parasites in the animal organism causes local and general modifications in the various organs they parasitize or transit throughout their life cycle. The present study aimed to identify the most frequent gastrointestinal parasites of dogs and cats and to monitor the alterations that occur in terms of haematological and biochemical parameters.

\section{Materials and Methods}

The studied animals were brought to the On-call room of the University Clinics of the Faculty of Veterinary Medicine "King Michael the Ist of Romania" from Timișoara, between April 2018 and April 2019. The representative species were $25 \mathrm{dogs}$ and three cats from Timiș and Caraș Severin counties. There were both pure bred and mixed breed animals, such as: German shepherd, Bucovina shepherd, Doberman, pincher, Alaskan malamute, viszla, Caucasian shepherd, Siberian husky, teckel, bichon, pug, poodle, Romanian mioritic shepherd, golden retriver, Shar Pei, Swiss shepherd, Siberian cats, European cats. The age of the animals ranged between: 2 months and 9 years and they were brought in for coproparasitic exams, with owners accusing to have noticed clinical signs specific for parasitic diseases, namely soft stools.

The laboratory methods that were used were the Willis flotation method, the Baerman larvoscopic method and the Lugol method [5,6].

The haematological methods, namely flow cytometry, cytochemistry and spectrophotometry, were performed at Bioclinica Laboratories, on whole blood samples that were collected in EDTA or simple tubes.

\section{Results}

The results of the parasitological exams highlighted pathogens that are sysmetically classified as part of the Protozoa, Cestoda and Nematoda classes. Thus, we have identified the following genera Giardia, Cystoisospora, Dipylidium, Ancylostoma, Toxocara and Trichocephalus.

Out of $25 \mathrm{dogs}$, four mixed breed and 21 purebred dogs, 11 were negative from a parasitololgical point of view and 14 were positive. As for the cats, two were positive for parasites (European) and one was negative (pure breed).

The concurrent infection with more than one species of parasites was observed in nine animals out of 28 taken into study (32.14\%), while monoparasitism was noticed in five animals (17.85\%) (fig. 1). In relation to the total number of animals taken into study, positive results were noticed in 16 animals, representing $57.14 \%$.

The prevalence according to the identified parasite species varied between $3.57 \%$ and $21.42 \%$, as seen in figure 2. 


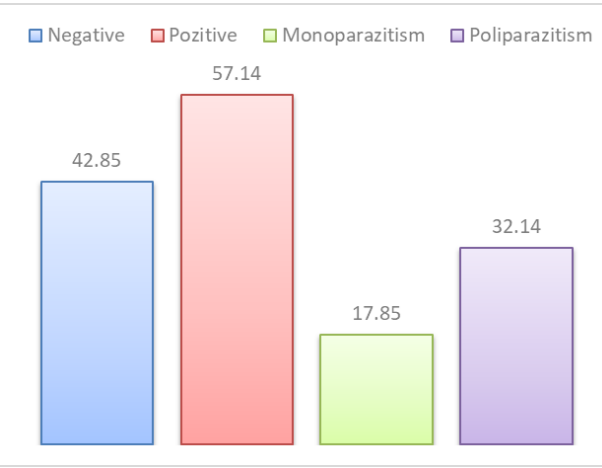

Figure. 1. Synthetic presentation of parasitism seen in the studied animals a parazitismului la animalele luate în studiu

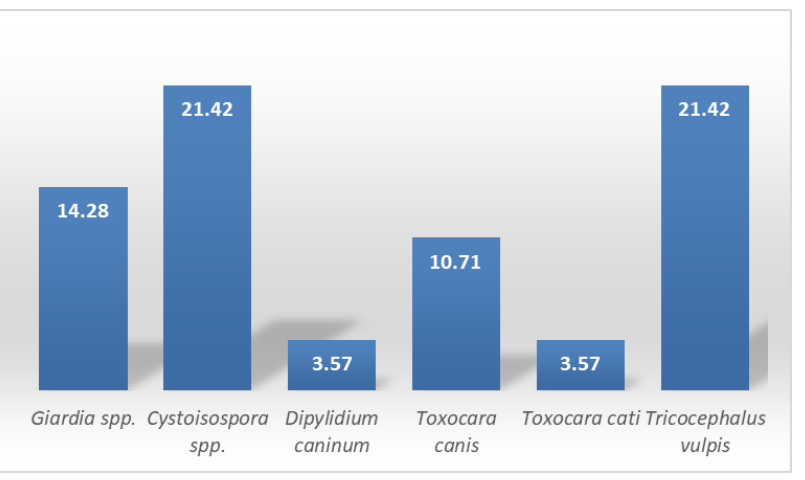

Figure. 2. Prevalence of the identified parasites in the studied animals

The haematological test values recorded for the 14 parasitized dogs are shown in figures 3-9.

The values recorded for red blood cells disclose the fact that the values from most dogs were within the minimal and maximal reference values, except for three of them that showed values below the minimal reference value. The values for red blood cells from one dog reached the maximal reference value.
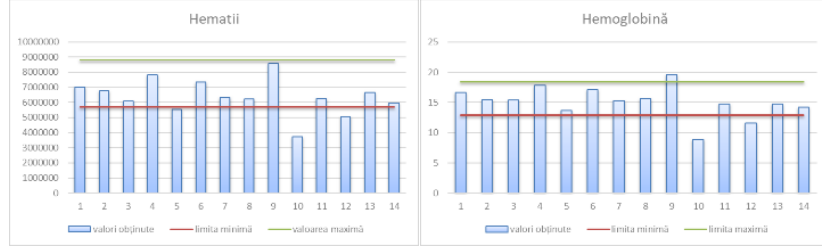

Fig. 3. Values recorded in the case of erythrocytes and haemoglobin

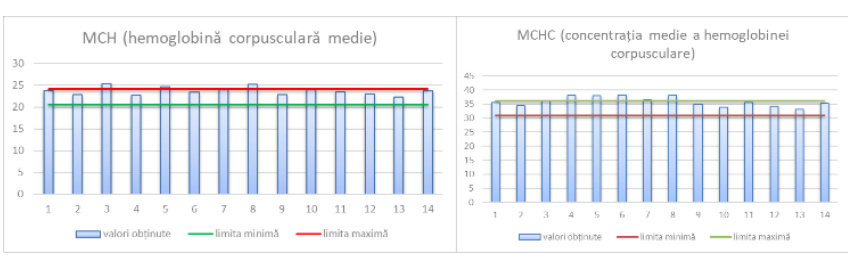

Fig. 5. Values recorded in the case of $\mathrm{MCH}$ and $\mathrm{MCHC}$
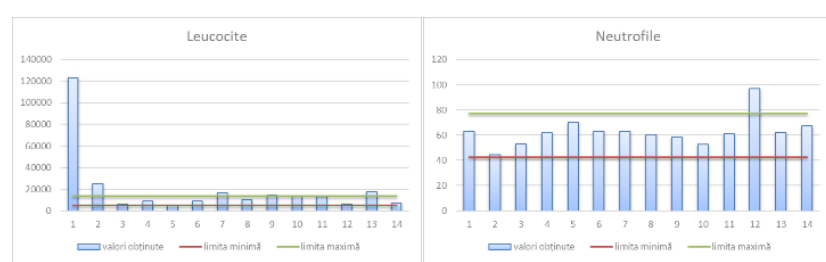

Fig. 7. Values recorded in the case of leukocytes and neutrophils

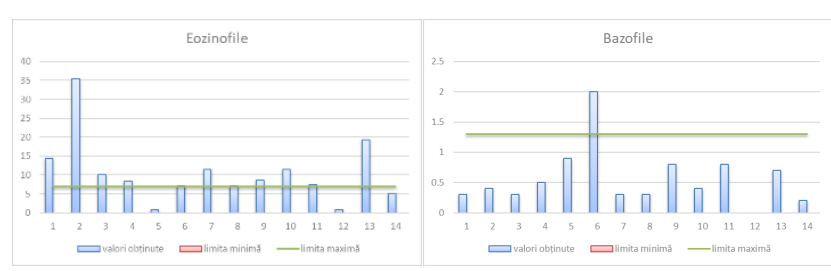

Fig. 9. Values recorded in the case of eosinophils and basophils

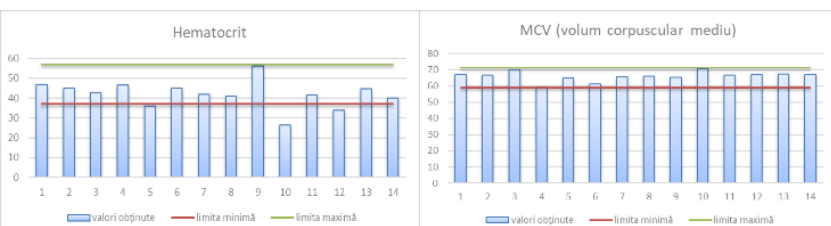

Fig. 4. Values recorded for the haematocrit and $\mathrm{MCV}$

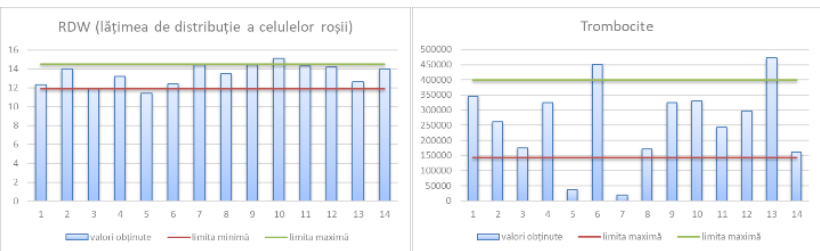

Fig. 6. Values recorded in the case of RDW and platelets
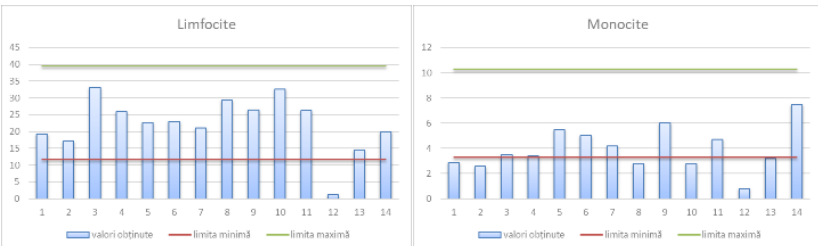

Fig. 8. Values recorded in the case of lymphocytes and monocytes

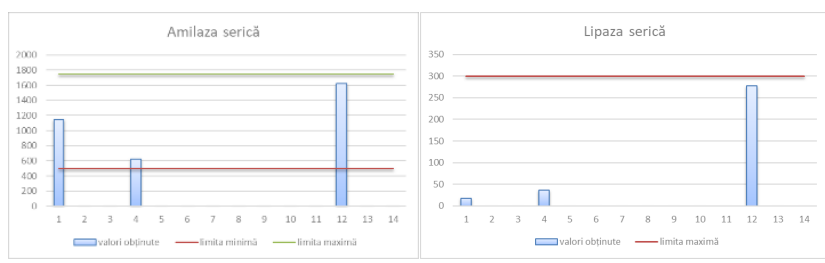

Fig. 10. Values recorded in the case of amilase and serum lipase 


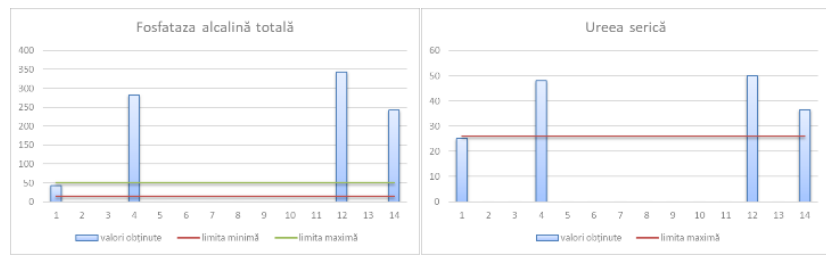

Fig. 11. Values recorded in the case of alkaline phosphatase and serum urea

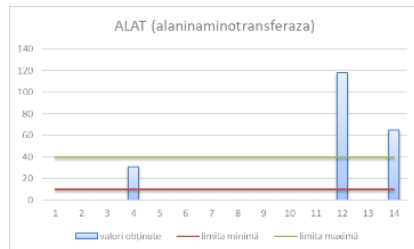

Fig. 13. Values recorded in the case of ALAT

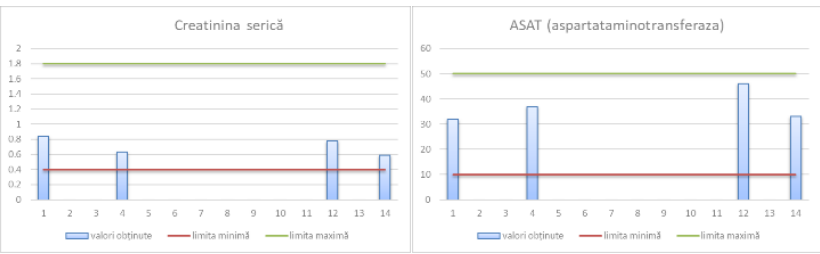

Fig. 12. Values recorded in the case of serum creatinin and ASAT

In the case of haemoglobin, similar to the evolution of the red blood cells values, most dogs overpassed the minimal value, except for two of them that showed values below minimum. One of the dogs had values surpassing the maximal threshold. The study of the haematocrit revealed that the recorded data followed a similar trend as that seen in erythrocytes and haemoglobin.

In the case of MCV (mean corpuscular volume), all dogs presented values that were within the physiological limits, however two of them reached maximal values.

In what regards the $\mathrm{MCH}$ (mean corpuscular haemoglobin), all dogs showed values above minimum, three of them showed maximum values and three showed values that were above maximum.

All dogs had MCHC (mean corpuscular haemoglobin concentration) values higher than minimum, five dogs reached the maximum level and four of them overpassed it.

The study of the RDW (red cell distribution width) revealed the fact that most dogs from the study have surpassed the maximum value, except for one which showed values below the minimal threshold. Three of them reached the maximum value and one of them overpassed it.

In the case of platelets, the noticed values were above the minimal threshold for most cases. Two cases exhibited values below minimum and other two cases had values above the maximum threshold.

The leukocyte values did not go below average values for none of the cases, three of them reached the maximum limit, other four overpassed it with one of them overpassing the limit by far. This fact can be explained by the presence of a chronic infection or of an overlapping bacterial infection which happen at the same time with the migration of parasites throughout the host's body, in case of leukemia or in case of severe stress.

As for the neutrophils, all dogs showed values within normal ranges, with a single case showing values above maximum.

The lymphocyte values for most dogs were above the minimal limit, except for one which showed values below limit. None of them showed values above maximum level.

The monocyte values of the studied dogs were above the minimal limit, except for five of them. None of the cases showed values below minimum.

The eosinophils were above minimum for all dogs, except for three of them and one of them had very high values.

The basophil values did not overpass minimal values except for one of the dogs. 
Biochemical analyses, in three, respectively four of the parasitized dogs, showed values that are presented in detail in figures 10-13.

Serum amylase values for the three studied dogs were all above minimum but below maximum.

Similarly, serum lipase was also below maximum levels.

Alkaline phosphatase in the case of the four studied dogs showed values above minimum, with three of them showing values above maximum. Following serum urea evaluation, it was revealed that all four studied dogs had values above the maximum reference level.

Serum creatinin for the four studied dogs revealed that all of the canine patients had values above minimum but below maximum.

AST varied similarly, with values above minimum but below maximum in all four dogs and ALT was evaluated in three dogs, all of them showing values above minimum, with two showing values above maximum as well.

\section{Discussion}

Mircean et al., 2012, identified the following parasites in dogs: Toxocara canis $26.9 \%$, Isospora ohioensis $23.1 \%$, Ancylostoma caninum 17.3\%, Uncinaria stenocephala 13.5\%, Trichocephalus vulpis $11.5 \%$, Hammondia heydorni/Neospora caninum 9.6\%, Sarcocystis spp. 9.6\%, Isospora canis 7.7\%, Capillaria aerophila 5.8\%, Strongyloides stercoralis 93.8\%, Dipylidium caninum 1.9\% and Toxascaris leonina 1.9\% [7].

In a study by Dărăbuș et al., 2018, eggs of Toxocara canis, Ancylostoma caninum and Trichocephalus spp. have been identified in varying proportions $(0.57 \%, 5.78 \%$ and $1.73-2.22 \%$, respectively) in dog faeces samples from parks.

Qadir et al., 2011 revealed a prevalence of $10.25 \%$ for mixed infections with Ancylostoma caninum, Toxascaris spp. and Dipylidium caninum and a 19.5\% overall prevalence of different species of the helminths [8].

In Argentina, faecal samples from 85 dogs were examined for intestinal parasites. Seventeen parasite species were seen, of which $77 \%$ are zoonotic. The most prevalent parasites were Ancylostoma caninum (68.2\%), Giardia spp. (25.9\%), Cryptosporidium spp. (20.0\%) and Toxocara canis (14.1\%) [9].

Bishop and DeBess, 2020, in Portland, Oregon, United States of America, determined the following prevalences: Toxocara canis $8.7 \%$, Strongyloides spp. $2.3 \%$, Trichuris spp. $2.1 \%$, hookworms (Ancylostoma caninum, Uncinaria sp., unspecified) 2.1\%, Cystoisospora spp. 1.4\%, Taenia spp. 1.2\%, Ancylostoma caninum $0.9 \%$, Uncinaria spp. $0.7 \%$, Baylisascaris procyonis $0.2 \%$, and Dipylidium spp. $0.2 \%$, in canine fecal samples [10].

A study conducted by Regidor-Cerrillo et al., 2020, in Spain, highlighted that microscopic, gastrointestinal parasite forms found in dog faeces were identified as nematodes (Ancylostomatidae, Toxocara canis, Trichuris spp. and Toxascaris leonina), cestodes (Taeniidae) and protozoa (Cystoisospora spp. and Giardia). From the 233 analysed dogs, 63.5\% were positive for at least one intestinal parasite, indicating a high degree of intestinal parasitism in these animals [2].

Significant decrease in the values of haemoglobin, total erythrocytic count, lymphocyte and marked leucocytosis, eosinophilia and neutrophilia were noted in pups that were naturally infected with toxocariosis. Post-treatment haematogical observations noted on day 7, 14 and 21 revealed that Toxocara infected dogs gradually returned to normal level but rapid and significant change towards normality were seen in Plozin (a combined tablet containing $500 \mathrm{mg}$ fenbendazole, $144 \mathrm{mg}$ pyrantel pamoate, $50 \mathrm{mg}$ praziquantel@1/2 tablet per $5 \mathrm{~kg}$ body weight) treated animals [11]. 
Voßmann (1985) examined the haemtaological alterations in pups, following prenatal infections as well as the numeric changes of red blood cells [12]. The number of red blood cells in the blood stream is low from a physiological point of view in newborn pups, rising in approximately 6-8 weeks post partum to reach the values seen in adult dogs. In contrast with this fact are pups which are heavily infected with T. canis. They showed decreasing values of erythrocytes, mainly caused by severe internal bleedings. The reason behind these internal bleedings were the preadult larvae, that migrated through the liver and perforated the intestine, all aspects caused by the massive parasitic load. Pups with moderate infections showed an increase in the number of erythrocytes starting with the $5^{\text {th }}$ week of life, but without reaching the values seen in non-infected animals. No changes in the numbers of red blood cells were noticed in adult bitches following infection with T. canis larvae [13]. Eosinophilia is characteristic in T. canis infections, starting from day 7 post infection and reaching maximum values within 14 days p.i. A similar evolution of eosinophilia is seen in pups infected in the prenatal period, starting with day 7 post partum [12]. Voßmann (1985) has also shown that the degree of eosinophilia in pups that were infected in the pre-natal period is almost proportional with the intensity of the infection [12]. Once the eggs start being shed in the faecal matters, the number of eosinophils slowly dropped, returning to physiological levels in 42 days p.i. These data have shown that the evolution of eosinophils in pre-natally infected pups is comparable to that of experimentally infected adult dogs [13].

Haematological changes are not the sole observations during infections with T. canis. Enzymatic alterations are also present thus, during the liver-migration period, the glutamate-dehydrogenase (GLDH) and alanintransaminase (ALT) rise, reaching maximum levels within 14 days p.i. [13]. After this peak, ALT stays at high levels for a certain period of time, while GLDH came back to normal values after 14 days [14].

Following reinfestation, hepatic enzymes show a new increase, although smaller in magnitude than during primary infection [13]. Voßmann (1985) noticed that these two enzymes, in pre-natally infected pups, were already high upon birth: $67 \mathrm{U} / 1$ for GLDH (reference values are up to 6,0 U / 1) and $365 \mathrm{U} / 1$ for ALT (reference values are up to $55 \mathrm{U} / 1$ ) in heavily infected pups [12]. Values came back to normal within 1-2 weeks post partum. A second increase in values caused by adult ascarids migrating through the liver and peritoneal cavity was detected shortly before the death of heavily infected pups.

The somatic migration in the lungs leads to multiple haemorrhagic petechia, forming a "tinted" pattern on the lungs [15]. The findings of Manhardt (1980) have confirmed that somatic migration is performed by larvae that are captured in the capillaries, larvae which penetrate their walls and migrate through the tissue in order to re-eneter the vascular system. This capacity to perform somatic migrations leads to the presence of larvae in organs founds in the vicinity of lungs and in the pleural cavity. Additionally, Manhardt (1980) has closely examined the kidney, an organ that is frequently affected by $T$. canis, noticing that severe organ failure is a rare sight in these situations. The larvae leave the blood vessels, namely the cortex, leaving small haemorrhages below the renal capsule, and begin a somatic migration. Some larvae go into the urinary canalicules, becoming detectable even in urine while others stay under the capsule after a short somatic migration and encapsulate in granulomas.

Shortly after beginning the hematogenous journey, larvae were also discovered in muscle fibers of the heart [15]. 


\section{Conclusions}

The carnivores that were taken into study were positive for pathogens from the Protozoa, Cestoda and Nematoda classes. The following genera were identified: Giardia, Cystoisospora, Dipylidium, Ancylostoma, Toxocara and Trichocephalus.

Compared to the toal number of examined animals, the positivity rate was $57.14 \%$, with prevalence rates according to the parasitic species ranging from $3.57 \%$ to $21.42 \%$, with multiparasitism in $32.14 \%$, and monoparasitism in $17.85 \%$.

The values recorded for red blood cells, haemoglobin and hematocrit followed the same trendmost of the animals being situated within physiological values, except for three dogs, that recorded values below the minimal level.

In the case of $\mathrm{MCH}$ (mean corpuscular haemoglobin) and $\mathrm{MCHC}$ (mean corpuscular haemoglobin concentration) the values recorded for most dogs were within physiological limits, except for three dogs which overpassed the maximum level.

Eosinophils were high in all dogs, which is a characteristic feature of parasitism.

The serum urea concentrations revealed the fact that all for dogs that were taken into study had values above the maximum limit.

Author Contributions: For research articles with several authors, a short paragraph specifying their individual contributions must be provided. The following statements should be used "Conceptualization, M.S.I. and R.G.O.; methodology, R.G.O; software, M.S.I.; validation, M.S.I. and R.G.O.; formal analysis, M.I, and I.L.; investigation, R.G.O, I.L. and S.G.; resources, T.S. and G.O; data curation, R.G.O. and G.O; writing-original draft preparation, M.S.I and T.S.; writing - review and editing, M.S.I and S.M.; visualization, T.S.; supervision, S.M.; All authors have read and agreed to the published version of the manuscript".

Acknowledgments: This study was performed using the support and infrastructure project „Dezvoltarea infrastructurii de cercetare, educaţie şi servicii în domeniile medicinei veterinare şi tehnologiilor inovative pentru RO 05", cod SMISCSNR 2669.

Conflicts of Interest: The authors declare no conflict of interest.

\section{References}

1. Nguyen T, Clark N, Jones MK, Herndon A, Mallyon J, Soares Magalhaes RJ, Abdullah S. Perceptions of dog owners towards canine gastrointestinal parasitism and associated human health risk in Southeast Queensland. One Health. 2021, 12:100226. doi: 10.1016/j.onehlt.2021.100226. PMID: 33665329; PMCID: PMC7903457.

2. Regidor-Cerrillo J, Arranz-Solís D, Moreno-Gonzalo J, Pedraza-Díaz S, Gomez-Bautista M, Ortega-Mora LM, CollantesFernandez E. Prevalence of intestinal parasite infections in stray and farm dogs from Spain. Rev Bras Parasitol Vet. 2020, 29(3):e014920. doi: 10.1590/S1984-29612020063. PMID: 32935772.

3. Luca I, Oprescu I, Morariu S, Mederle N, Ilie M S, Darabus G. Effects of some disinfectants on Toxocara spp.eggs viability of dogs and cats. Turk J Vet Anim Sci 2020 44: 734-739

4. Qadir, S., Dixit, A. K., Dixit, P., \& Sharma, R. L. Intestinal helminths induce haematological changes in dogs from Jabalpur, India. Journal of Helminthology, 2010, 85(04), 401-403. doi:10.1017/s0022149x10000726

5. Dărăbuş, Gh., Oprescu, I., Morariu, S., Mederle, N., Ilie, M., Ghid practic în bolile parazitare, Vol. I, Agroprint, Timișoara, 2013, ISBN 978-606-8037-25-7

6. Dărăbuş, Gh., Oprescu, I., Morariu, S., Mederle, N., Ilie, M., Ghid practic în bolile parazitare, Vol. II, Agroprint, Timișoara, 2013, ISBN 978-606-8037-25-7 
7. Mircean V, Györke A, Cozma V. Prevalence and risk factors of Giardia duodenalis in dogs from Romania. Vet Parasitol. 2012, 184(2-4):325-9. doi: 10.1016/j.vetpar.2011.08.022. PMID: 21899952.

8. Dărăbuș Gheorghe, Luca Iasmina, Oprescu Ion, Morariu Sorin, Mederle Narcisa, Ilie Marius, Sachter Yacov, Pollution with parasitic elements of green areas in Timișoara, Sci Parasitol 2018, 19(1-2):62-65,

9. Enriquez GF, Macchiaverna NP, Argibay HD, López Arias L, Farber M, Gürtler RE, Cardinal MV, Garbossa G. Polyparasitism and zoonotic parasites in dogs from a rural area of the Argentine Chaco. Vet Parasitol Reg Stud Reports. 2019, 100287. doi: 10.1016/j.vprsr.2019.100287. Epub 2019 Apr 8. PMID: 31027600.

10. Bishop GT, DeBess E. Detection of parasites in canine feces at three off-leash dog parks in Portland, Oregon 2014. Vet Parasitol Reg Stud Reports. 2020, 100494. doi: 10.1016/j.vprsr.2020.100494. Epub 2020 Nov 7. PMID: 33308738.

11. Sharma Sanjeev Kumar, Sinha S.R.P., Sinha Sucheta, Jayachandran C., Kumar Mukesh Post-treatment haematological studies on toxocariosis in dogs, Journal of Veterinary Parasitology, 2010, 24, 1, 63-65.

12. Voßmann, M.T., Klinische, hämatologische und serologische Befunde bei Welpennachpränataler Infektion mit Toxocara canis WERNER 1789 (Anisakidae). Doctoral Thesis. University of Veterinary Medicine Hannover, Hannover, 1985, Germany, pp. $1-58$.

13. Zimmermann, U., Quantitative Untersuchungen über die Wanderungund Streuung der Larven von Toxocara canis WERNER 1782 (Anisakidae) imdefinitiven Wirt (Beagle) nach fraktionierter Erstund Reinfektion. Doctoral Thesis. University of Veterinary Medicine Hannover, Hannover, Germany, 1983, pp. 1-77.

14. Schnieder T., Laabs E.M., Welz C., Larval development of Toxocara canis in dogs, Vet. Par. 2011, 175, $193-206$.

15. Manhardt, J., Das Verhalten von Larven von Toxocara canis WERNER 1782 (Anisakidae) während und nach der Lungenwandering imdefinitiven Wirt (Beagle). Doctoral Thesis, University of Veterinary Medicine Hannover, Hannover, Germany, 1980, pp. 1-76. 